\section{0th Anniversary Celebrations of Atomic-Resolution Imaging}

Thomas F. Kelly and Allan J. Melmed

October 2005 marks 50 years since the first images achieving atomic resolution were obtained by Erwin Müller and Kanwar Bahadur at the Pennsylvania State University using field ion microscopy. An image from that seminal work is shown in Figure 1. Two separate meetings were held this year to commemorate this important event in the history of microscopy; the $50^{\text {th }}$ Anniversary of Atomic Resolution Microscopy, held June 15-17, 2005 at Penn State and the Golden Anniversary of Atomic Resolution Imaging, a symposium at Microscopy and Microanalysis 2005 in Honolulu held July 31 to August 4,2005. These celebrations were timed to coincide also with the World Year of Physics 2005 http://www. wyp2005.org/.

\section{Penn State Meeting}

The 50th Anniversary of Atomic Resolution Microscopy was held at the Nittany Lion Inn on the campus of the Pennsylvania State University. The conference was intended to commemorate and celebrate the $50^{\text {th }}$ anniversary of the achievement of atomic resolution microscopy that occurred there on October 10, 1955. About 50 experts representing all of the atomic resolution microscopies from around the world gathered to discuss the origins and important applications of each microscopy, and firmly established the historical facts of the first achievement of atomic resolution microscopy by field ion microscopy (FIM). In addition, the meeting put into perspective the entire field of atomic resolution microscopy and explicitly recognized the profound influence of Erwin W. Müller's work on the development of each of the atomic resolution microscopies and on the entire field of Surface Science. A highlight of this meeting was the presence of Dr. Kanwar Bahadur, Figure 2, who gave a first hand account of the events and excitement that lead to the very first images such as Figure 1.

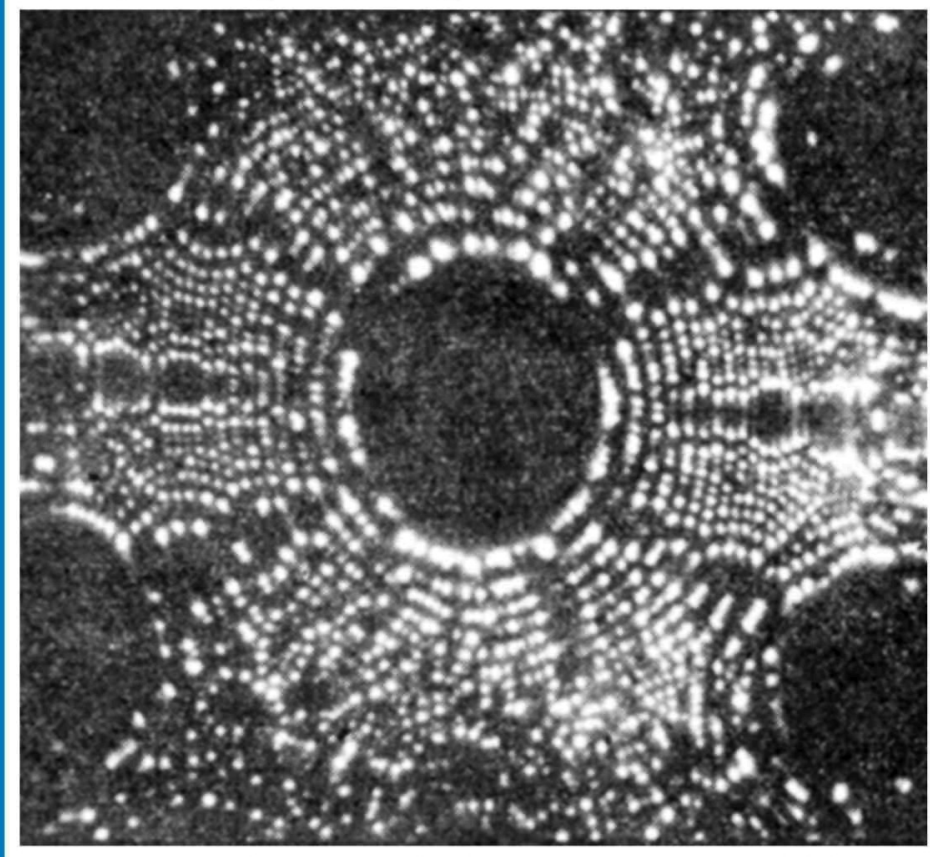

Figure 1 Field ion image of a rhenium surface recorded with helium ions at liquid nitrogen temperature. The individual bright spots in the image are rhenium atoms on the surface. This is one of the first atomic resolution images ever recorded.
Welcoming speeches were given by Daniel J. Larson, Dean, Eberly College of Science, the Pennsylvania State University, Professor Milton Cole for the Department of Physics, Dr. Richard Forbes, President, International Field Emission Society, and Dr. Gracie Burke, President, Microscopy Society of America.

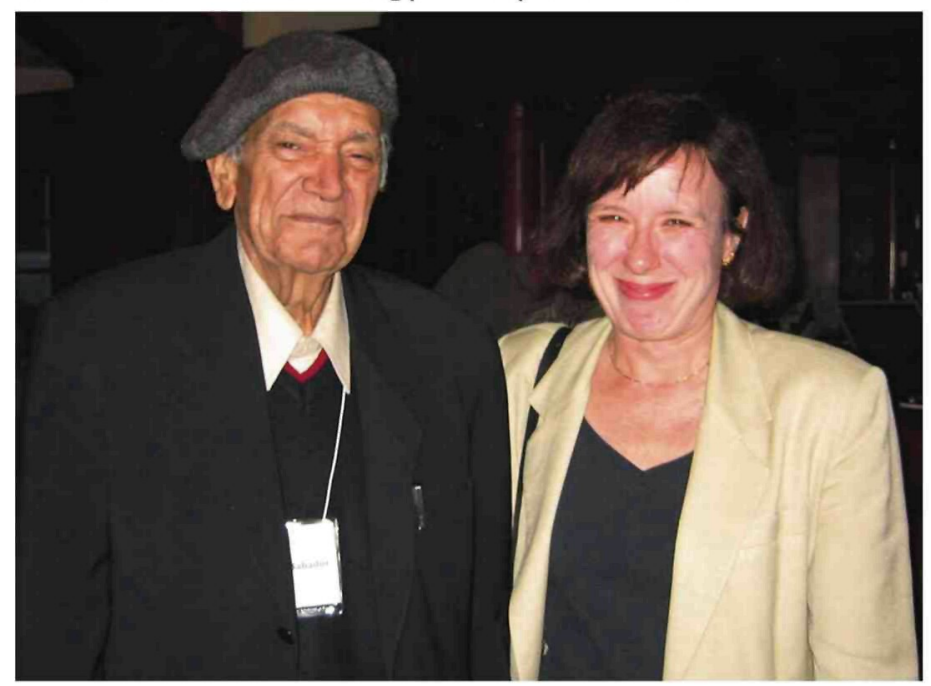

Figure 2 The guest of honor, Dr. Kanwar Bahadur with Dr. Gracie Burke, MSA President. Kanwar was a graduate student in Müller's laboratory and obtained the first atomic resolution image.

There was an opening get together offered by the conference sponsors at which many of the participants shared reminiscences. It had been many years since some of the participants had encountered each other. Some of the participants in the opening get together are shown in Figure 4. One of the unscripted excursions at lunchtime led to the former laboratory of Professor Müller by some of his former students. Figure 4 is a picture taken at the entrance to this laboratory. A bronze plaque and the laboratory door call notice to this historic location.

A generous amount of funding for the conference was kindly provided by:
Cameca Instruments Inc.
Carl Zeiss SMT
FEI Company
Imago Scientific Instruments Corporation
International Field Emission Society
JEOL USA, Inc.
National Science Foundation
Nion Company
Oxford NanoScience Ltd.
The Penn State College of Engineering

A compilation of the many excellent talks presented at the meeting has been prepared for distribution on CD in an effort to document the proceedings of the meeting. There are many historical micrographs and photographs in this collection of talks. These CDs may be purchased at cost by going to the website, www.msa. microscopy.com and looking for " $50^{\text {th }}$ Anniversary Celebration."

\section{M\&M Presidential Symposium}

The symposium at M\&M 2005 was sponsored by the Presidents of the Microscopy Society of America, the Microbeam Analysis Society and the International Field Emission Society. This two-day symposium was organized to reach a broader audience of microscopists and attracted hundreds of attendees. Speakers were invited to describe the technology of atomic resolution microscopy in field ion 


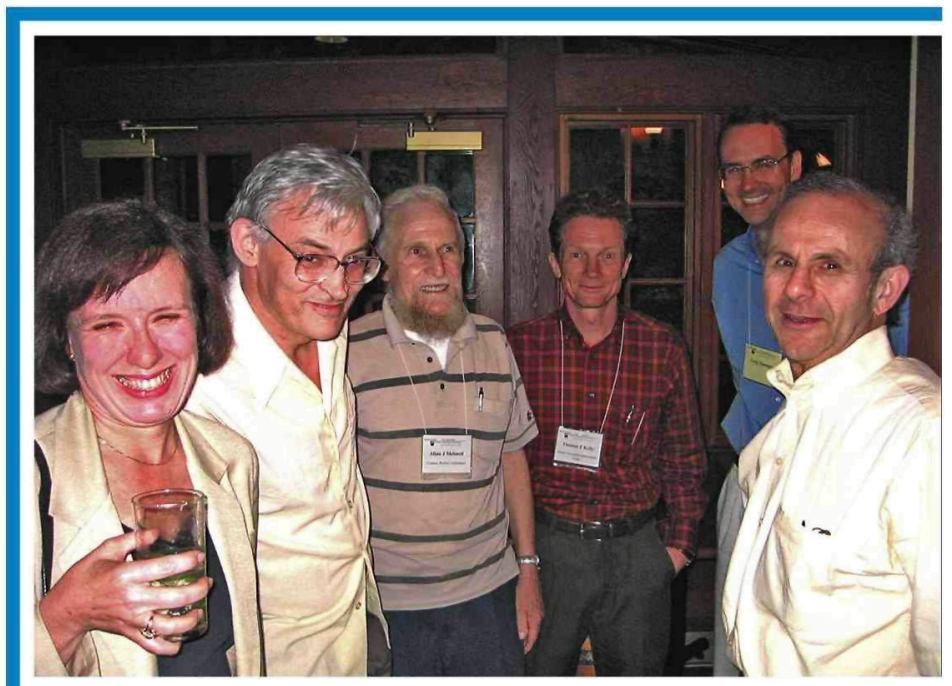

Figure 3 Some of the participants in the Penn State meeting opening get together. From left to right: Gracie Burke, Richard Forbes, Allan Melmed,

Thomas Kelly, Greg Thompson, and David Seidman.

microscopy, transmission electron microscopy, and scanning probe microscopy and the many applications of the sharp tips that are a common ingredient to each. The use of sharp tips in ion sources displays, and other applications was also explored.

Corporate sponsors for the M\&M Presidential Symposium include:

Imago Scientific Instruments Corporation

Cameca

Oxford nanoSciences, Ltd.

FEI Company

Oak Ridge National Laboratory

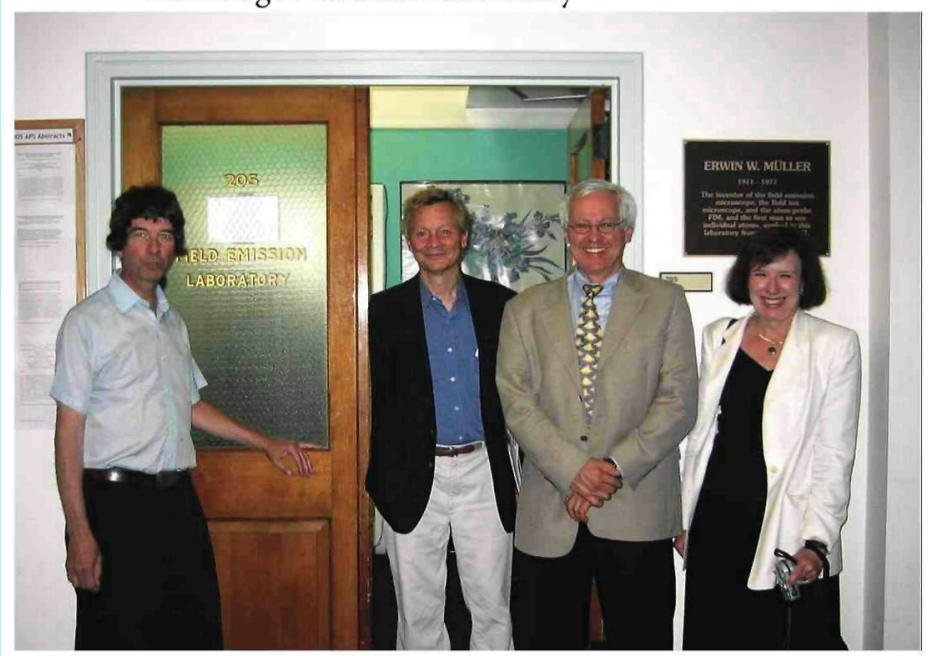

Figure 4 The entrance to Professor Müller's laboratory at the Pennsylvania State University. From left to right: John Panitz, Max Lagally, Ondrej Krivanek, and Gracie Burke. Note the commemorative plaque on the wall.

\section{Commemorative Poster}

As part of the festivities, a group of experts from the sponsoring organizations created a commemorative poster to mark this important milestone. It traces the history of atomic resolution imaging from the earliest concepts of atoms by Democritus to the present day. This poster was prepared as a service to the community and is being sold by the organizing societies on a cost-recovery basis. See the accompanying ad for how to get one of these special posters or visit www.msa.microscopy.com and look for "50"th Anniversary Celebration."
Commemorative Poster Available Now

Celebrating the $50^{\text {th }}$ Anniversary of Atomic Resolution Imaging

Imaging Atoms:

\section{An Odyssey}
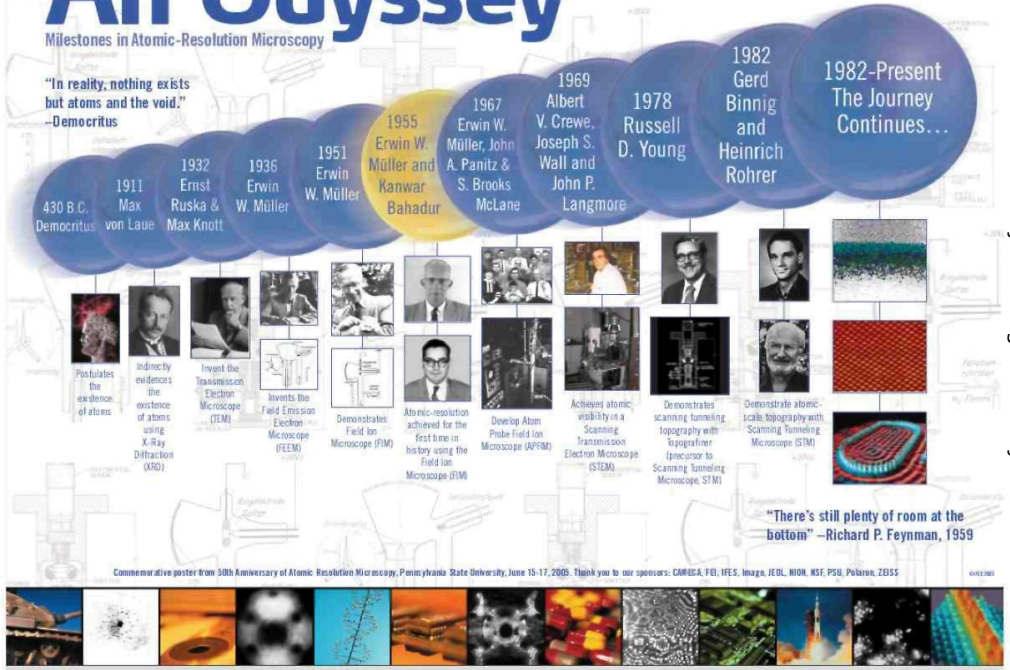

Glossy poster suitable for framing $(28 \times 22$ inch $)(71 \times 56 \mathrm{~cm})$

A "must have" for the well-equipped microscopy laboratory Sold at cost $(\$ 10)$ by

the Microscopy Society of America and

the International Field Emission Society

Visit www.microscopy.org to get yours today!

\section{Nano-Fabrication Specialist} Xradia, Inc. Concord, CA.

$R \& D$ advanced $\mathrm{X}$-ray optics fabrication tech \& execute SBIR research projects.

PhD degree required.

Resume fax president (925) 288-1299

or apply www.xradia.com 